\title{
Research on Core Competence Construction and Evaluation Index System for University Teachers Based on Modern Education
}

\author{
Xuelian Lu \\ Tonghua Normal University, College of Education Science, Jilin Province, Tonghua City, \\ 134002, China. \\ luxuelian1982@sina.com
}

\begin{abstract}
Teachers are the core resources of education, and teachers' abilities directly affect the quality of talent cultivation in universities. With the characteristics of open and innovative lifelong education, modern education has put forward new requirements for the ability of university teachers. The core competence construction of University Teachers based on modern education should cover six major competencies, namely, teaching leadership, organizational management, learning and innovation, collaboration and cooperation, honesty and self-discipline, physical and mental adaptability. The evaluation index of teachers' ability should be constructed to define the basic quality of teaching and management that teachers should possess and the basic level to achieve, so that teachers are worthy of the great trust of devoting themselves into improving the quality of talent cultivation.
\end{abstract}

Keywords: university teachers, ore competence, bility evaluation, modern education.

\section{基于现代教育的高校教师核心能力建设与考评指标体系研究}

\section{陆雪莲}

通化师范学院教育科学学院, 吉林通化 中国

摘 要: 教师是教育最核心的资源, 教师能力直接影响学校人才培养的质量。现代教育以开 放创新的终身教育为特征, 对高校教师能力提出了新要求。基于现代教育的高校教师核心能 力建设应涵盖教师的六大能力, 即教学领导能力、组织管理能力、学习创新能力、团结协作 能力、廉洁自律能力、身心适应能力, 并要构建教师能力的考评指标。明确教师应具备的教 学与管理的基本品质和要达到的基本水平, 使教师不负重托, 为提升人才培养质量贡献自身 的力量。

关键词：高校教师、核心能力、能力考评、现代教育.

\section{1. 前言}

现代教育背景下要重新调整教师核心能力, 能力内容要进一步拓展。具有良好职业能力的教 师既应是一名优秀的知识传授者, 又应是一名优秀的身教影响者, 对于学生的言行举止、道 德观和价值观都会起到特殊作用。

\section{2. 高校教师核心能力的内容及考评}

\section{1. 高校教师核心能力的内容}

2.1. 1 高校教师的教学领导能力

教学领导能力是教师坚定不移地推进课堂教学改革, 领导教学活动, 把握人才培养目标, 使 教学活动有效运转以取得预期目标的一种教学力量。 
教师教学领导能力的构成要素有: 一是深厚的理论功底。理论成熟是教学成熟的基础。理论 素养的高低, 特别是运用理论解决实际问题的能力, 是衡量教师教学领导能力成熟程度的重 要标志。二是坚定的教学立场。教学立场取决于教师角色, 教师要始终坚持 “真诚地为学生 着想” 的原则, 师生间始终保持 “接通” 状态。三是鲜明的教学观点。教学观点是教师对有 关教育问题的看法和主张, 是课堂教学改革的基础。教师没有正确的教学观点就失去了教师 教学的灵魂。四是严明的教学纪律。教学纪律是教师在教学过程中表现出的一种行为规范, 是自身素养在教育领域中的具体化和规范化, 体现了教师行为的示范性。五是高超的教学技 能。教学技能是教师教学素养在行为外化过程中的表现, 是教师运用理论而形成稳固复杂的 教学行为, 并可以达到自动化水平。六是高尚的思想品德。教师的思想品德是国家法律、社 会道德在教师的思想、情感、行为中内化、固化形成的素养，是教师的首要素养。

教学领导能力是教师履行教学职责的内在要求, 提升教师的教学领导能力必须重点把握: 注 重理论武装, 坚持理论联系实际; 着眼现代教育的新要求, 增强教师思想品德建设的力度; 加强教师自身建设, 树立与教学领导能力相适应的观念、作风和意识; 坚持依规领导, 提高 教学领导能力的规范性与示范性。

\subsection{2高校教师的组织管理能力}

组织管理能力是教师按照教学职责, 对课堂教学过程中所涉及的各种教学要素进行调控, 以 实现教学目标的能力。

教师组织管理能力的构成要素有: 一是高效率交往的能力。教学是教师 “教” 与学生 “学” 的统一, 而这种统一的实质便是交往。二是激发学习动机的能力。学生是学习的主人, 学习 动机对学习效率的提升至关重要, 教师对学生学习动机的培养和激发是教师工作的重要任务。 三是营造教学环境的能力。课堂是学生创新潜能得以实现的重要场所, 教师需要给学生提供 宽松、民主的课堂教学环境, 使学生身心获得自由, 实现其创新潜能。四是教学评价的能力。 评价目的为是改进教学, 教师要构建目标多元、方式多样、过程连续、注重改进的课堂教学 评价体系, 对教与学进行全面评价。

教师组织管理能力是实现教学目标的重要保障, 提升教师的组织管理能力必须重点把握: 提 升教师教学实践, 完善实践经验的总结; 发挥教师创造性, 提炼组织管理模式; 注重教学风 格的独特性, 增强个性化管理的优势。

\section{1.3 高校教师的学习创新能力}

学习创新能力是教师以教学目标为指引, 主动获取知识信息并融合相关素材, 对教学进行思 维运作和创新性实践, 推动教学新成果的能力。

教师学习创新能力的构成要素有: 一是创新知识的获取。教师要提高知识的质量、增强知识 的能量、完善知识的结构、激发知识的活力, 准确掌握信息获取、选择、加工、去伪存真的 本领。二是学习创新意识的培养。学习创新意识主要是由好奇心、求知欲、怀疑、创新需要、 创新动机组成, 各项对教师学习创新意识均具有引发功能。三是学习创新思维的形成。学习 创新能力要求教师思维做到 “四个善于” ，即善于从新角度审视问题、善于联想认知问题、 善于多向分析问题、善于解决问题。四是学习创新实践的成效。学习创新能力的生成和发展 是随着学习创新实践的不断深入而发展的, 不能离开创新性实践。

教师学习创新能力是实现教学质量提升的不竭动力, 提升教师的学习创新能力必须重点把握: 培育学习创新的新观念, 提高对教育问题的理解; 养成学习创新的新思维, 解决教育实践的 难点问题; 夯实学习创新的新能力, 实现创新的教学能力。

\subsection{4高校教师的团结协作能力}

团结协作能力是教师为更好地实现教学目标而采取不同方法与手段, 协调各方面教育资源和 力量以达到相互配合, 形成最大教育合力的能力。

教师团结协作能力的构成要素有: 一是主体的能动性。教师在主观意识上要以团结、友谊为 重, 从团结与合作的愿望出发, 主动去理解人、尊重人。二是内容的广泛性。团结协作贯穿 
于教学活动的全过程与全环节, 需要教师多种能力共同发生作用。三是功能的综合性。团结 协作能力是一个多功能的综合体，教师要把各方面的组织和人员团结协调起来，保证团结协 调功能的实施。四是表现的差异性。团结协作能力体现在不同教师身上具有个体差异性, 这 种差异对完成教学活动效率有影响。五是发展的独立性。团结协作能力在本质上是一种创造 性活动，受教师素质的制约，但其一但形成，就具有了相对的独立性。

教师团结协作能力是保证教学活动顺利完成的重要手段, 提升教师的团结协作能力必须重点 把握：主动了解沟通艺术，实现及时有效的交流；勇于负责不推过，发扬民主不霸道; 增强 团结协作的自觉性，多做促进团结协作的工作；着眼大局主动合作，善于妥协求同存异。

\section{1.5 高校教师的廉洁自律能力}

廉洁自律能力是教师严格按照教师行为规范自觉地约束自己的行为, 确保自己在任何情况下 都能坚持执教为学生、廉洁奉教的一种约束力和控制力。

教师廉洁自律能力的构成要素有: 一是履行廉洁自律的责任。教师既要高标准要求自己, 又 要教育引导其他人廉洁自律。二是行使廉洁自律的权力。教师既要提高自己在学生中的威望, 又要形成导向, 为廉洁自律营造良好环境。三是健全廉洁自律的制度。建立廉政建设的制度, 是提高教师廉洁自律能力的根本。四是加强廉洁自律的道德建设。道德与制度建设要双管齐 下、相得益彰，才会收到事半功倍的成效。

教师廉洁自律能力是教师树立教学形象、展示教师鬼未的重要途径, 提升教师廉洁自律能力 必须重点把握: 加强思想教育, 增强廉洁自律的自觉性; 强化自身修养, 树立正确的师德; 完善制度规范，健全检查监督机制；加强廉政文化建设，营造廉洁自律的环境。

\subsection{6高校教师的身心适应能力}

身心适应能力是教师的身体素质和心理素质对教学工作需求的满足与适应程度。

教师身心适应能力的构成要素有: 一是智力正常。正常智力水平是教师生活、学习、工作最 基本的条件。二是情绪稳定。情绪稳定表明中枢神经系统处于相对的平衡状态，意味着机体 功能的协调, 这是教师心理健康的重要标志。三是意志坚强。行动的自觉性和果断性是教师 意志坚强的重要标志。四是行为协调。心理健康的教师, 其行为有条不紊, 做事按部就班, 思想与行动统一协调。五是人际关系融洽。人际间正常友好的交往不仅是维持心理健康必不 可少的条件, 也是教师获得心理健康的重要方法。六是反应适度。教师对外界刺激的反应不 能超过一定的限度, 过度的反应则是心理失常的先兆。

教师身心适应能力是教师其他能力得以正常发挥的重要基础, 提升教师的身心适应能力必须 重点把握：增强自我培养意识, 按照优秀教师必备的身心素质标准来要求和锤炼自己; 加强 训练, 提升身心适应能力; 认真学习深入研究，掌握身心调控的理论知识。

\section{2. 高校教师核心能力的考评}

\subsection{1高校教师核心能力考评的指标框架}

构建以扩大民主为基础的参评主体体系。探索教师核心能力的考评，首先要研究参与教师能 力评价的主体。要建立一个以扩大民主为基本理念, 以责任度、关联度和知情度为基本原则, 以各教学利益相关方参与的全方位、立体式的教师核心能力考评的主体体系。

构建以核心能力标准为中心的考评内容体系。构建科学的考评内容体系, 解决好考评六大项 能力的问题, 准确反映教师核心能力的基本情况, 教师才会有明确的努力方向, 各教学利益 相关方也才能以此来判定某位教师核心能力的强弱。

构建以定性与定量相结合为手段的考评方法体系。考评方法在考评体系的构成中处于重要地 位, 影响着考评的成败。在教师核心能力考评中, 考评方法决定着考评体系其他环节的设计, 同时研究考评方法也是教师核心能力考评中最具有创新空间的部分。 
构建以考评结果的有效运用为目标的考评结果运用体系。运用好考评结果是考评工作的生命 力所在。教师核心能力考评对于教师的积极作用, 主要体现在考评结果的运用上。要以考评 结果为基本依据, 正确调配与使用教师。

\subsection{2高校教师核心能力考评的组织实施}

考评工作能否收到好的效果, 能否真正做到对教师考实评准, 不仅要有一套科学的考评办法, 同时还必须有一套与之相适应的科学严密的考评组织实施办法和程序。一要成立考评委员会 或领导小组, 并确定主要职责。二要做好考评前的工作准备, 其核心是制定方案。三要组织 好考评活动的具体实施。四要有效避免考评误差, 使考评过程客观准确。

\section{3. 结论}

教师是高校教学过程的指导者, 指导学生走向知识、走向社会、走向生活。教师核心能力不 仅体现在实施教学的行为过程中, 更体现在教师的心理倾向、思想水平、人格鬼力和知识的 渊博度等方面。建立具有特色的、科学的教师核心能力考评机制, 是实施学校人才战略工程 的重要任务。

\section{致谢}

1.通化师范学院2017年教师专业发展研究项目《基于现代教育的高校教师核心能力建设与考 评指标体系研究》阶段性成果。

2. 吉林省 “十三五” 教科规划课题《基于核心素养视角的师范生职业核心能力培养研究》阶段 性成果。

\section{References}

[1]. Shouren Wang, Linmiao Shi. Focusing on the Improving of Teachers' Teaching Abilities Pushing Ahead with the Construction of the Teacher Education Development Center[J]. China University Teaching 2016,4, P75-80.

[2]. Yuexin Cao, Bowei Zhang. Research on the cultivation of College Teachers' teaching ability[J]. Journal of Northeast Normal University(Philosophy and Social Sciences Edition). 2016,2,P208213.

[3]. Jing He. Research on the optimization of teaching ability evaluation mechanism of University Teachers[J]. Heilongjiang Researches on Higher Education.2015,1, P95-98.

[4]. Yu Tao, Congmin Ren. Research on the path and strategy of Higher Vocational Teachers' teaching ability development. Higher education research[J].2015,11, P50-54. 